\title{
Information Systems Outcomes based Assessment at Jouf University for ABET Accreditation
}

\author{
A. A. Abd El-Aziz \\ Dept. of Information Systems \\ College of Computer and Information Sciences Jouf University, KSA \\ Email: aaeldamarany@ju.edu.sa FGSSR, Cairo University, Egypt
}

\section{Saleh N Almuayqil}

Dept. of Information Systems

College of Computer and Information Sciences Jouf University, KSA Email:snmuayqil@ju.edu.sa

\author{
Ahmed Alsayat \\ College of computer and Information Sciences Jouf University, KSA Email:asayat@ju.edu.sa
}

\section{Madallah Alriwili}

College of computer and Information Sciences Jouf University, KSA Email:madallah@ ju.edu.sa

Article History: Received: 10 November 2020; Revised 12 January 2021 Accepted: 27 January 2021; Published online: 5 April 2021

\begin{abstract}
The Accreditation Board for Engineering and Technology (ABET) Criteria for Computing Accreditation Commission Programs are based upon knowledge, presentation skills, communication skills, team work and leadership skills that the students gain through the curriculum in a program. The student outcomes (SOs) are the procured skills and knowledge which the student accomplishes through the curriculum. Each program needs to have its own SOs and to evaluate it as per defined assessment cycle, just as to accomplish program educational objectives (PEOs). The continuous improvement plan depended on assessment and evaluation of the program SOs and PEOs. In this paper, an advancement cycle for continuous improvement, for Information systems (IS) program at College of Computer and Information Sciences (CIS), Jouf University, Sakaka, Aljouf, Saudi Arabia, to accomplish the accreditation is discussed. The proposed cycle is appropriate to get the accreditation for bachelor program in information systems discipline and to fulfill the ABET criteria. In result, we will show how the SOs and PEOs were surveyed and assessed through curriculum accordingly. Based on these processes, ABET team has visited CIS college, which had accomplished extraordinary achievement and all of the programs have completely accredited on August 2018 and the next visit to the computing and engineering programs will be on 2026.
\end{abstract}

Keywords-ABET, Student outcome, Program educational objectives, Assessment, Evaluation, Continuous Improvement, .

\section{INTRODUCTION}

The ABET Accreditation process is performed by four accreditation commissions. Each commission sets accreditation norms for explicit program areas and degree levels [2]. ABET 
accreditation guarantees that the program has gained international acknowledgment of its quality. Accreditation is a voluntary certified system for computing programs, managed by perceived professional bodies. It is likewise a positive move towards making sure about legitimacy, granting accredited computing programs their meriting honor and regard through continued proceeded with proficient advancement. Internationally, ABET has been thought of as one of the profoundly regarded bodies that lead this cycle.

ABET Criteria tends to the effectiveness of computing education programs by zeroing in on an assessment and evaluation [4], [8], [10], [11], [12], [13] measure that guarantees the accomplishment of a bunch of educational objectives and outcomes. A significant component of these criteria is the foundation of a continuous improvement process. Outcomes based assessment process centers around what the students learned or what they really can do at the time of graduation. In its accreditation criteria, ABET Criteria for Computing depends upon the knowledge, presentation skills, communication skills, team work and leadership skills that the students evolve through the curriculum in a program.

Jouf University is multi-campus university comprising of three campuses in Sakaka, Tabarjal and Qurayyat. Moreover, every campus comprises of two sections one for male students and one for female students. However, all programs (Computer Science, Information Systems and Computer Engineering and Networks) in the CIS College are indistinguishable for the two sections. Each section has its own vice-dean yet common departments head and one Dean of faculty for the two sections. With an end goal to improve and keep up the quality of computing and engineering education offered by the CIS's programs, the College CIS started external assessments conducted by the ABET. This cycle was arranged at first to ensure that what the programs offer, are identical to their peer programs around the world, moreover, to fulfill the alumni and society needs.

To satisfy ABET criteria; IS program set up the PEOs and SOs. This has experienced number of preliminaries and changes made by IS department council. The Industrial Advisory Committee (IAC) and the program alumni were the primary tools for the evaluation of PEOs and SOs, while faculty and exit students evaluated only the SOs. Assessment of PEOs and SOs show ordinarily he qualities and shortcomings of the entire educational process. Accordingly, continuous improvement processes were set to expand on the qualities and to beat the shortcomings. Moreover, the improvement cycle should present the available documentation processes normally utilized in making decisions with respect to program improvement. The implementations of these methodologies were made by re-examining the curriculum, teaching methods, lab facilities [3]. In this paper, an advancement cycle for continuous improvement for IS program is introduced. The proposed cycle is pertinent to get the accreditation for bachelor program in information systems discipline and to fulfill the ABET criteria. In result, we will show how the SOs and PEOs assessed and evaluated through curriculum accordingly.

\section{CRiteria 1:StUdents}

Jouf University has unified affirmation methodology for conceding also, following the advancement of all students through the Deanship of Admissions and Registration. These rules depend on also, steady with the overall principles of the Saudi Arabian Ministry of Education are accessible on the Deanship of Admissions and Registration site at http://dar.ju.edu.sa/structures/list laws E.pdf. All, reasonable students are at first conceded by the Deanship of Admissions and Registration to a Common First Year (CFY) where students must learn fundamental courses completely trained by English language before being admitted to their ideal faculties. Up to June 2019, an aggregate of 249 students have registered in the IS program. 


\section{A. Student Admissions}

The University Council determines the number of students to be admitted in the upcoming academic year according to the recommendations of Colleges' Councils. Selection of admitted students from applicants who meet all admission requirements is taken on the basis of their grades in the general secondary certificate, personal interviews and admission tests (if any).

\section{B. Evaluating Student Performance}

The IS program is a semester system. Every academic year comprises fundamentally of two academic semesters and every academic semester has length of 15 weeks. Moreover, there is one summer semester with length of about two months. In summer semester, the duration of each course is twice its duration of a regular academic semester. The IS program is a four-year program with one year for Common First Year. Student progresses in the study in accordance with the implementation rules approved by the University Council. Study plans for the undergraduate study are designed for a minimum of eight semesters. The grades of semester works are calculated by two written tests at least, quiz, homework, mini project and presentations. Student's grade obtained in each course is calculated as follows:

TABLE I

GRADING SYSTEMS AT JOUF UNIVERSITY

\begin{tabular}{|c|c|c|}
\hline Letter of Grade & Mark & Average Point \\
\hline A + & 95 & 5.00 \\
\hline A & $90-94$ & 4.75 \\
\hline B+ & $85-89$ & 4.50 \\
\hline B & $80-84$ & 4.00 \\
\hline C + & $75-79$ & 3.50 \\
\hline C & $70-74$ & 3.00 \\
\hline D+ & $65-69$ & 2.50 \\
\hline D & $60-64$ & 2.00 \\
\hline F & Below 60 & 1.00 \\
\hline
\end{tabular}

\section{Advising and Career Guidance}

An Academic student guide is available in Arabic language on the website of the Deanship of Admission and Registration, the URL is: http://dar.ju.edu.sa/forms/Acadmic Student.pdf. One of the academic advising objectives is to guarantee that students enrolled in the program, satisfy all the university, faculty and department requirements and graduate on schedule. To understand this, it is imperative to keep up a continuous monitoring of the academic performance and progress of the students, and whenever required, students are advised on the course choices that they should register in every semester. This monitoring is encouraged through a study plan created by the department. Each student as provided with an academic guide from the same department as long as the student remains in the college. The academic guide exhorts the student until his graduation. The academic guide observes the student's achievement, redresses any blunders what's more, noticed lacks, controls the student in arrangement of the graduation plan and assists with choosing the elective courses and appropriate subject for senior plan project to meet his graduation plan. Other responsibilities of the academic advisors may include:

- Monitoring the absence of the student: Monitoring the absence of students from the functions of the professor of the course, and the academic advisor to follow up cases referred to him by the coordinators guidance in accordance with the plan.

- Coaching about students' add and drop of courses procedures.

- Providing students with direct and indirect access to the expertise of college members outside the classroom.

- Advise the students of their career opportunities. 


\section{Career Guidance}

Workshops are conducted during the studying for students in the early stages of how to choose a career path. Moreover, in each academic year prior to the commencement of the practical examinations, the college participates in the professional day. On a professional day, several workshops are held to teach students how to write a C.V., how to conduct interviews and how to choose the right job. On a professional day, the university invites a group of companies specializing in Information Technology, where they are presented with graduation projects for senior students and graduates.

\section{E. Graduation Requirements}

A student graduates after completion of the graduation requirements successfully according to the study plan, provided that his/her cumulative GPA is no less than pass grade. The graduation requirements for bachelor degree in IS are depicted in Fig. 1:

\begin{tabular}{|c|c|c|c|}
\hline \multicolumn{3}{|c|}{ Requirements } & Credit Hours \\
\hline 1 & \multicolumn{2}{|c|}{ University Requirements } & 20 \\
\hline 2 & \multicolumn{2}{|c|}{ College Requirements } & 39 \\
\hline \multirow[t]{2}{*}{3} & \multirow{2}{*}{ Program Requirements } & Core & 63 \\
\hline & & Elective & 12 \\
\hline \multirow[t]{2}{*}{4} & \multicolumn{2}{|c|}{$\begin{array}{c}\text { Common First Year (not included in IS } \\
\text { program) }\end{array}$} & 34 \\
\hline & \multicolumn{2}{|c|}{ Total Credit Hours for IS Program } & 134 \\
\hline
\end{tabular}

Fig. 1. Graduation Requirements for Bachelor Degree in IS

\section{F. Transfer Students and Transfer Courses}

The transfer requirements are available on the website of the Deanship of Admission and Registration, the URL is: http://dar.ju.edu.sa/forms/list laws E.pdf. The transfer of a student from outside the University or from one College to another could be approved if the student satisfies the rules set out by the Deanship of Admission and Registration and approved by the University Council. Moreover, a student may transfer from one major to another within a college, upon the Dean's approval, in accordance with the rules set out by the University Council.

\section{Criteria 2: Program Educational OBJECTIVES (PEOS)}

ABET's evaluation of a program essentially begins with the evaluation of how PEOs help in achieving the institution's mission. Therefore, ABET requires discussion on how PEOs are consistent with the mission of the institution and is there a review process in place for the PEOs. Meeting this requirement may require some revision of the PEOs and the mission. In our case we had to rewrite the mission and PEOs.

\section{A. Jouf University Mission}

Providing distinguished education and research outcomes to develop the community. 


\section{B. College Mission}

Preparation of qualified scientific cadres in the various fields of computing through innovative education and scientific research, which develops creative and analytical abilities that can serve the society.

\section{Department Mission}

Preparation of qualified scientific cadres in the various fields of information systems through innovative education and scientific research, which develops creative and analytical abilities that can serve the society.

\section{Program Educational Objectives (PEOs)}

The program with its different constituents examined the ABET requirements for the improvement of the PEOs in progressive meetings by focusing on the principle components of the university's mission, for example, innovative information, research and expert community services. Each one of those components is the key center purposes of PEOs of the IS program. Those PEOs will assist with imagining the future of potential and current students selected the IS program. After a few departmental meetings, the department with assistance of its constituents affirmed the accompanying PEOs, in that the IS program graduates are set up to:

- PEO-1: Contribute to the development of growth of the society by applying Information System in various domains.

- PEO-2: Advance in their careers by starting their own business or as managers in organizations by applying information systems \& communication skills in the evolving business and technological issues.

- PEO-3: Continue their professional development through advanced studies and research.

1) Consistency of the Program Educational Objectives with the Mission of the Institution: The department knew that the created PEOs serve the mission of the Jouf University as appeared in Fig. 2 The department's PEOs are centered around key components of the Jouf university's mission by conveying the students with basic information, devices and aptitudes of science and innovation to meet the key prerequisites of public and private association. Moreover, they improve the knowledge and expertise based culture to serve different communities while decidedly sway the environment.

\begin{tabular}{|c|l|l|l|}
\hline \multicolumn{5}{|c|}{ Jouf University's Mission } \\
\hline PEOs & $\begin{array}{l}\text { Providing Creative } \\
\text { Knowledge }\end{array}$ & $\begin{array}{l}\text { Excellence in } \\
\text { Teaching and Research }\end{array}$ & $\begin{array}{l}\text { Professional Services } \\
\text { with Effective } \\
\text { Community } \\
\text { Partnership }\end{array}$ \\
\hline PE0-1 & $\sqrt{ }$ & & $\sqrt{ }$ \\
\hline PEO-2 & $\sqrt{ }$ & $\sqrt{ }$ \\
\hline PEO-3 & $\sqrt{ }$ & $\sqrt{ }$ \\
\hline
\end{tabular}

Fig. 2. Consistency of PEOs with Jouf Universitys Mission

\section{E. Program Constituencies}

The program constituencies are those who must be satisfied with the performance of the IS program. The significant groups of constituencies of the IS program are included but not restricted to students, alumni, faculty and employer and most importantly to the program Industrial 
Advisory Committee:

- Faculty: IS faculty members are involved on regular basis in the assessment processes.

- Students: current IS students are interested in whether the IS program adequately prepares them for future employment.

- Alumni: this group consists of recent graduates who have been employed for most two years. They should have the incentives to assess the quality of PEOs based on their career achievements.

- Employers (government, industry and universities): employers' satisfaction with our students' education provides measure of the program success. Their satisfaction translates to employment opportunities for our students.

- Industrial Advisory Committee (IAC): this group plays a major role in program evaluation, advising, improvement, and development.

The following figure shows how IS PEOs meet the needs of its constituencies:

\section{F. Process for Review of the Program Educational Objectives}

The IS program uses the following process to periodically review the program educational objectives so that they remain consistent with Jouf University mission, the different constituents' needs, and the ABET CAC criteria:

1) The program reviews the PEOs and may produce a draft for a new PEOs formulation under the he most proficient method to improve the program.

2) The program disperses surveys to students, the program Alumni and faculty members looking for their assessment with respect to the ampleness of the PEOs.

3) The contribution from the past constituencies is investigated statistically and another PEOs draft is created.

4) The new proposed PEOs are discussed and endorsed by the department council. The last affirmed PEOs will at that point be distributed in all the program reports (site, handouts, announcement, and so forth).

\begin{tabular}{|c|c|c|c|c|}
\hline Constituent & Needs & PEO-1 & PEO-2 & PEO-3 \\
\hline \multirow[t]{2}{*}{ Faculty } & $\begin{array}{l}\text { Provide up-to-date } \\
\text { knowledge }\end{array}$ & $\sqrt{ }$ & & $\sqrt{ }$ \\
\hline & $\begin{array}{l}\text { Involvement in community } \\
\text { service or teaching }\end{array}$ & $\sqrt{ }$ & & \\
\hline \multirow[t]{2}{*}{ Students } & $\begin{array}{l}\text { Involvement in life-long } \\
\text { learning process }\end{array}$ & $\sqrt{ }$ & $\sqrt{ }$ & $\sqrt{ }$ \\
\hline & Get a suitable job & & $\checkmark$ & \\
\hline \multirow[t]{2}{*}{ Alumni } & $\begin{array}{l}\text { Involvement in life-long } \\
\text { learning process }\end{array}$ & $\sqrt{ }$ & $\sqrt{ }$ & $\sqrt{ }$ \\
\hline & Enhance job experience & & $\sqrt{ }$ & \\
\hline \multirow[t]{2}{*}{ Employers } & $\begin{array}{c}\text { Teamwork or individual } \\
\text { work } \\
\text { without assistance }\end{array}$ & & $\sqrt{ }$ & \\
\hline & Communication skills & & $\sqrt{ }$ & \\
\hline $\begin{array}{c}\text { Industrial Advisory } \\
\text { Committee (IAC) }\end{array}$ & $\begin{array}{l}\text { Qualified graduates for } \\
\text { potential job market. }\end{array}$ & $\sqrt{ }$ & $\sqrt{ }$ & \\
\hline
\end{tabular}

Fig. 3. Mapping of Constituents' Needs to PEOs 
following circumstances:

a) A change in the University mission. A request for change coming from members of one or more of the programs main constituencies.

b) A change in the ABET CAC [1] criteria affecting the PEOs

c) A change in the vision of national and international professional societies regarding information systems practice.

d) Under all circumstances, however, a major periodic review of the PEOs will be conducted every three to four years.

5) The department council meeting discusses the new PEOs draft and may suggest some changes.

6) The assessment of the program fundamental constituencies is looked for:

- The department sorts out a meeting of the Program Advisory Committee to survey the PEOs. After conversation, the individuals from the Advisory Committee round out a study about the sufficiency of the proposed PEOs and any suggestions on the most proficient method to improve the IS program.

- The department welcomes agents from the primary businesses of the program graduates for a meeting to audit the PEOs corresponding to their requirements. After a conversation about the arrangement between the proposed PEOs and the businesses' necessities, the businesses round out the PEOs overview frames and compose their conclusions on

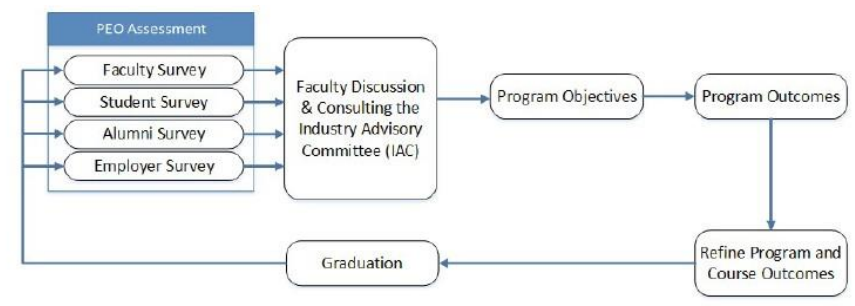

Fig. 4. Process for Review of the Program Educational Objectives

\section{G. Criteria 3: Student Outcomes (SOs)}

The IS department met and examined the ABET Computing Accreditation Commission 1-to6 general measures (SOs) and the program standards and arrived at the resolution that ABET SOs 1-6 adequately meet the program prerequisites. They are related to knowledge, skills and behavior that students will acquire through the program. The student outcomes support the PEOs [9], [5] and the mission of the University, the college and the department. The following are the Student Outcome of IS program:

1) Analyze a complex computing problem and to apply principles of computing and other relevant disciplines to identify solutions.

2) Design, implement, and evaluate a computing-based solution to meet a given set of computing requirements in the context of the programs discipline.

3) Communicate effectively in a variety of professional contexts.

4) Recognize professional responsibilities and make informed judgments in computing practice based on legal and ethical principles.

5) Function effectively as a member or leader of a team engaged in activities appropriate to the programs discipline.

6) Support the delivery, use, and management of information systems within an information systems environment.

1) Relationship of SOs to PEOs: Each SO is surveyed inside the IS program. Accomplishment of SOs can lead to the achievement of the PEOs and they are an indispensable condition for 
achieving the PEOs as introduced in Table 2. The faculty members of the IS program apply the results of SOs assessment to improve, create and redesign the program.

TABLE II

Relationship of Student Outcomes to PEOs

\begin{tabular}{|c|c|c|c|}
\hline SOs & PEO-1 & PEO-2 & PEO-3 \\
\hline 1 & & & \\
\hline 2 & & & \\
\hline 3 & & & \\
\hline 4 & $v$ & & \\
\hline 5 & & & \\
\hline 6 & $v$ & & \\
\hline
\end{tabular}

\section{CRITERION 4. CONTINUOUS IMPROVEMENT}

Continuous improvement is performed by two cycles, assessments and evaluation. The IS program utilizes various apparatuses and cycles to survey and assess the degree to which its SOs are being accomplished. These cycles are utilized to assemble the information which is important for the evaluations. Evaluation, as deciphering the data, is then done to decide how well the results are being accomplished. The consequences of both the assessment and evaluation measures are at long last used for the continuous improvement of the IS program. The means utilized for the assessment, evaluation and criticism to the continuous improvement of the program follow the accompanying three stages:

1) Assessment apparatuses of the SOs (i.e., gathering data) can be direct or indirect. Direct assessment of SOs typically depends on the course work, though indirect assessments of SOs are typically acquired by utilizing reviews. This progression incorporates planning types of studies and suitable inquiries for the particular and pertinent information.

2) The gathered data is investigated and compared to a pre-set performance marker, which comprises the assessment processes.

3) Checking how much the data assessment results meet the pre-set targets will be the power for the continuous improvement processes.

\section{A. Student Outcomes}

In order to assess and evaluate the extent to which the SOs are being attained, the IS program uses various processes. These processes are defined to keep data gathering efficient and effective, and the evaluation pertinent to the process of continuous improvement. To achieve these goals, two types of assessments, direct and indirect are performed [3], [7]. The indirect assessment is performed using surveys while the direct assessment results are obtained from student coursework based evaluations. The direct- and indirect-assessment methods used by the IS to regularly assess and evaluate the extent to which the student outcomes are being attained, are illustrated in Fig. 5:

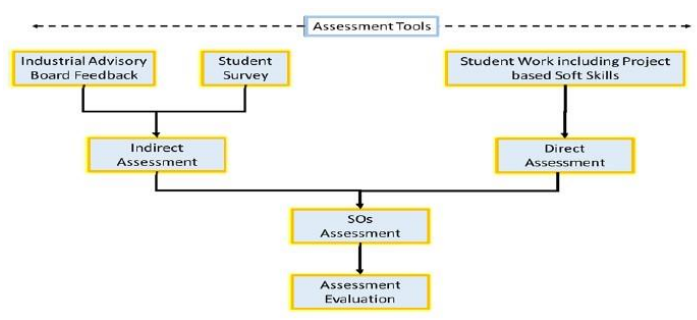

Fig. 5. Assessment Process

\section{B. Indirect Assessment}

For our indirect assessment, different surveys are conducted. Course student survey is conducted 
towards the end of a course. In this regard, formal written surveys targeting the sought outcomes are solicited from students at the end of the IS courses. The surveys are conducted by the faculty members in their respective classes. The indirect assessment is conducted in every semester.

TABLE III

Tools used By the Program for Indirect Assessments

\begin{tabular}{|c|c|c|}
\hline Assessment Tool & Frequency of Assessment & Expected Level of Attainment \\
\hline Student Surveys & Semester & $60 \%$ \\
\hline Exit Surveys & Semester & $60 \%$ \\
\hline
\end{tabular}

\section{Direct Assessment}

The direct assessment of the outcomes usually relies on the coursework and uses a variety of tools that include combinations (as defined in the articulation matrix at the beginning of academic year) of final exam, midterm tests,quizzes, homework, laboratory works, assignments, practical, projects, presentations, etc. The assessment tools are varying from course to course.

TABLE IV

Tools used by the Program for Direct Assessments

\begin{tabular}{|c|c|}
\hline No. & Assessment Tool \\
\hline 1 & Homework / Assignments \\
\hline 2 & Quizzes \\
\hline 3 & Mid-term Exams \\
\hline 4 & Group (Individual) Project Rubric Based \\
\hline 5 & Lab Exam / Lab Activities \\
\hline 6 & Student Portfolio \\
\hline 7 & Presentation \\
\hline 8 & (Comprehensive) Final Exam \\
\hline
\end{tabular}

\section{Fall Semester(2018-2019) Assessment}

1) Direct Assessment: The cycle of assessment of SOs is done utilizing a few mixes course work, for example, assignments, mid-term, final exams, quizzes, presentations and projects where the accomplishments on these practices are straightforwardly attached to SOs. The assessment is done each time a course is given. The following Fig. 6 and Fig. 7 describe the direct assessment of course CS 409 as an example:

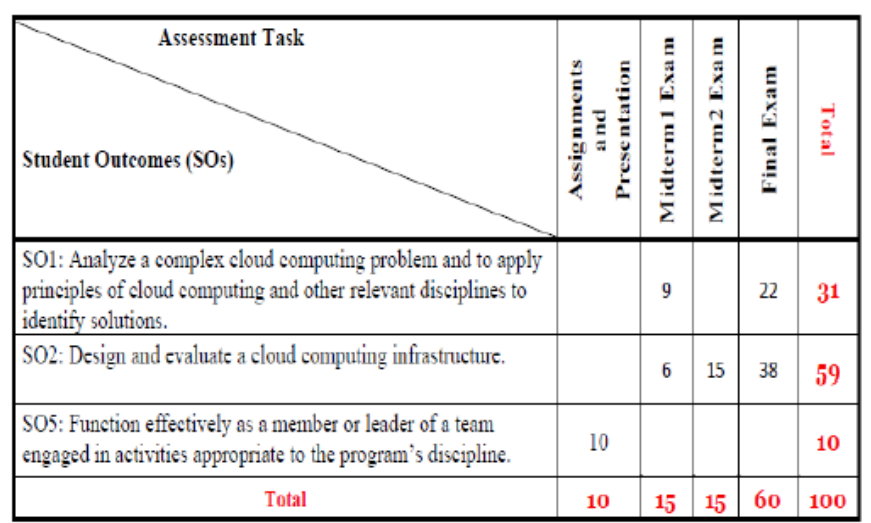

Fig. 6. Distribution of Assessment Grades of the Course CS 409 


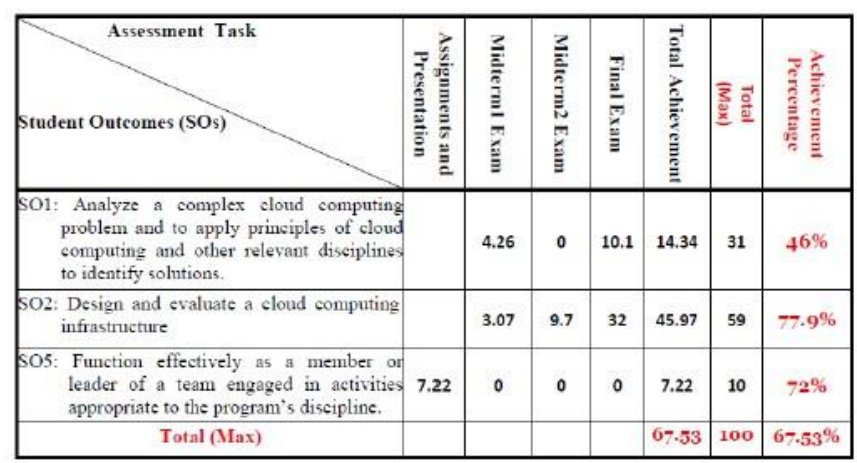

Fig. 7. Achievement of Assessment Grades of CS 409-Fall

The outcomes in Fig. 7 are explained below in Fig. 8 as a graph of the level of accomplishment of the course's outcomes $\mathrm{SO} 1, \mathrm{SO} 2$ and $\mathrm{SO} 5$ and contrasted with the pre-set achievement level of $60 \%$.

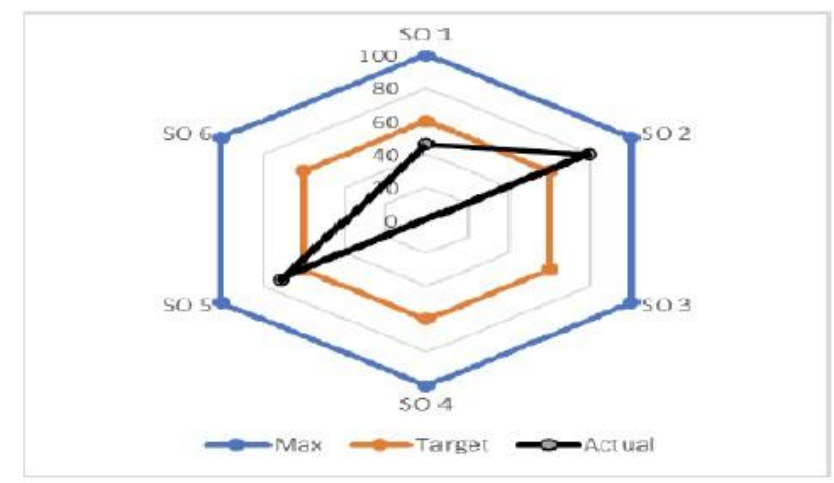

Fig. 8. Direct Assessment of Course CS 409-Fall 2018-2019

Investigation of the Fig. 8 reveals that the $\mathrm{SO} 2$ and $\mathrm{SO} 5$ are sufficiently higher than their target, but the SO1 is less than its target. Hence, the SO1 needs to be improved in the next semester.

2) Indirect Assessment: At the end of the semester, the students are asked to assess the courses they have taken, with specific accentuation on the level of fulfillment of the focused on SOs through questions dependent on fitting KPI. This cycle is on the web. Let us, indeed, decide for representation the course CS 409. The students, who finished this course, are approached to answer a bunch of the inquiries as depicted in Fig.

9. These inquiries are identified with the particular SOs SO1, SO2 and SO5. The crude data gathered from the students' assessment is put away in and broke down progressively and electronically and the results are passed to the faculty member and HOD for additional assessment and taking proper decision. The results got for the course CS 409 were summed up in Table 5: 


\begin{tabular}{|l|l|l|l|l|l|}
\hline & \multicolumn{3}{|c|}{ Strength of Coverage } \\
\hline $\begin{array}{l}1.1 \text { Your ability to formulate the problem specifications from the } \\
\text { problem definition. }\end{array}$ & & & & \\
\hline $\begin{array}{l}1.2 \text { Your ability to specify the software tools needed for a given } \\
\text { problem/5oftware developtnent: Language, Packages and Operating } \\
\text { System. }\end{array}$ & & & & & \\
\hline $\begin{array}{l}1.3 \text { Your ability to specify the hardware requirements for a computer } \\
\text { based system. }\end{array}$ & & & & \\
\hline $\begin{array}{l}1.4 \text { Your ability to specify the data analyzing as well as to analyze the } \\
\text { issues of the technology of Information Systems. }\end{array}$ & & & & \\
\hline $\begin{array}{l}\text { 1.5 Your ability to identify, define and analyze different technology of } \\
\text { Information Systems. }\end{array}$ & & & & \\
\hline
\end{tabular}

Fig. 9. A sample of a Student Survey

TABLE V

INDIRECT ASSESSMENT OF COURSE CS 409-FALL 2018-2019

\begin{tabular}{|c|c|c|c|}
\hline & SO1 & SO2 & SO5 \\
\hline Weight Average & 3.96 & 3.91 & 4.13 \\
\hline Achievements Percentage & 79.10 & 78.23 & 82.60 \\
\hline
\end{tabular}

This table shows the average got for every one of the SOs $\mathrm{SO} 1, \mathrm{SO} 2$ and $\mathrm{SO} 5$ from their overview inquiries on the size of 1 to 5 with 5 being the best and afterward traded to rate and demonstrated graphically in Fig. 10. Examination of Fig. 10 uncovers that the SOs SO1,

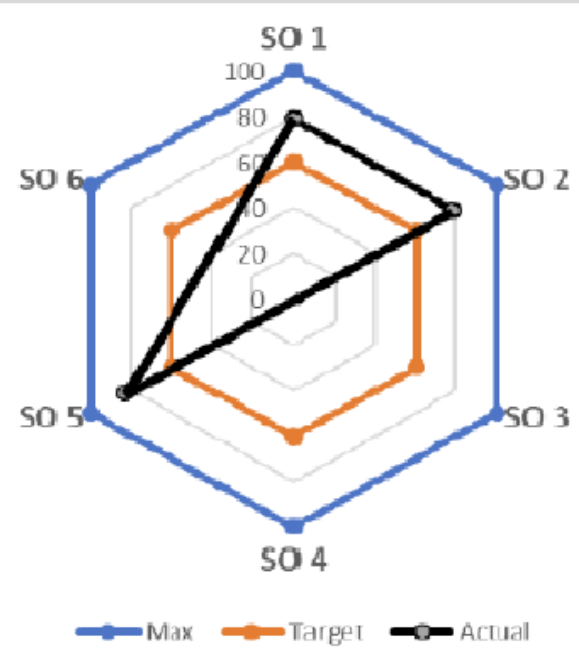

Fig. 10. The Indirect Assessment of Course CS 409-Fall 2018-2019

$\mathrm{SO} 2$ and $\mathrm{SO} 5$ are over their expected values. This 
shows a reasonable difference to the direct assessment of the courses done by the IS department members, which is very sensible as the students are not that certain to evaluate themselves precisely the manner in which they acted in the academic year. The cycle of the indirect assessment of courses was done for all fall-semester offered courses in a similar style as accomplished for CS 409. In this manner, IS department members choose the suggestions for development and to be led during the following spring semester. Besides, the IS department members additionally considered all courses that didn't meet their accomplishment levels for additional examination and proposals for improvements.

\section{E. Comparison of Semesters Assessment Results}

The above direct and indirect assessments performed for the fall semester 2018-2019 was carried out for the spring semester 2018-2019. Hence, for comparing the direct assessment results of fall 2018-2019 and spring 2018-2019 semesters, Fig. 11 indicates the average of direct outcome achievement for the two semesters.

\begin{tabular}{|c|c|c|c|c|}
\hline SO & Max & Target & Fall 18-19 & Spring 18-19 \\
\hline 1 & $100 \%$ & $70 \%$ & $63 \%$ & $66 \%$ \\
2 & $100 \%$ & $70 \%$ & $68 \%$ & $67 \%$ \\
\hline 3 & $100 \%$ & $70 \%$ & $70 \%$ & $71 \%$ \\
\hline 4 & $100 \%$ & $70 \%$ & $84 \%$ & $84 \%$ \\
\hline 5 & $100 \%$ & $70 \%$ & $82 \%$ & $78 \%$ \\
\hline 6 & $1110 \%$ & $711 \%$ & $66 \%$ & $69 \%$ \\
\hline
\end{tabular}

Fig. 11. A Comparison of SOs using Direct Assessment

\section{F. Analysis of Fall and Spring 2018-2019 Semesters Assessment Results}

1) Direct Assessment: The two-semester comparative results of students' accomplishment taken from direct assessment were shown in Fig. 11. This figure displays the degree of SOs achievement in the fall semester when contrasted with the SOs level of fulfillment in the spring semester. At the end of the spring semester, the Quality Assurance and Academic Accreditation Unit of the College of Computer and Information Sciences evaluated the results. It discovered that all the Sos of the program were around the benchmark (70\%). This accomplishment is because of the incredible endeavors offered by all the IS department members during the year 2018-2019. In an examination between the two semesters, it is clear that the SOs SO2 and SO5 in the spring semester have lower esteems than that in fall semester, while the excess Sos have higher values in the spring semester. This affirms that the education cycle is considered as a dynamic cycle and its SOs rely upon the course type.

2) Indirect Assessment: The consequences of students' overview for two-semester of the academic year 2018-2019 recommend that students' viewpoint on their accomplishment of the SOs is acceptable, in light of the fact that the entirety of the 1-6 SOs are over the base degree of accomplishment $(60 \%)$ as required. This is on the grounds that it was the first occasion when that the department utilizes the indirect assessment for the proposed courses. In spite of the fact that the pre-owned review has been acquainted with the studnets and its point has been clarified, students may misjudge that the overview is associated with the department member assessment. Accordingly, a meeting with the students will be organized right on time in the following semester to explain the goal and the substance of the indirect assessment process.

3) Continuous Improvement Methodology: IS SOs are driven mostly by the ABET criteria and by the PEOs that are lined up with Jouf University's mission. The PEOs set a rule for program SOs, educational plan advancement and teaching methodology. To guarantee accomplishment of the SOs, an assortment of assessment tools as examined were utilized. The degree of assessment and evaluation measure is led toward the end at each semester, and the outcomes of this assessment 
cycle are utilized to improve the teaching cycle to accomplish the focused on SOs. The cycle is presented below in Fig. 12 which shows assessment and the evaluation cycle, and thus closing the circle, of SOs. Note that evaluation is made at two various levels, course-level and program level. The result of evaluation is used as criticism for development and fused into intending to improve the general fulfillment of SOs. In the following, each component of closing the loop process is briefly explained in turn:

4) Planning: At the start of every semester (Fall/Spring), each course team (including course coordinator and instructors) arranges a course coordination meeting. In these meetings, which are properly documented, previous semester's end-of-semester reports (submitted by each instructor and coordinator of the course) are discussed and appropriate changes are made in the course, including for example adjustments in the assessment plan. Course-level

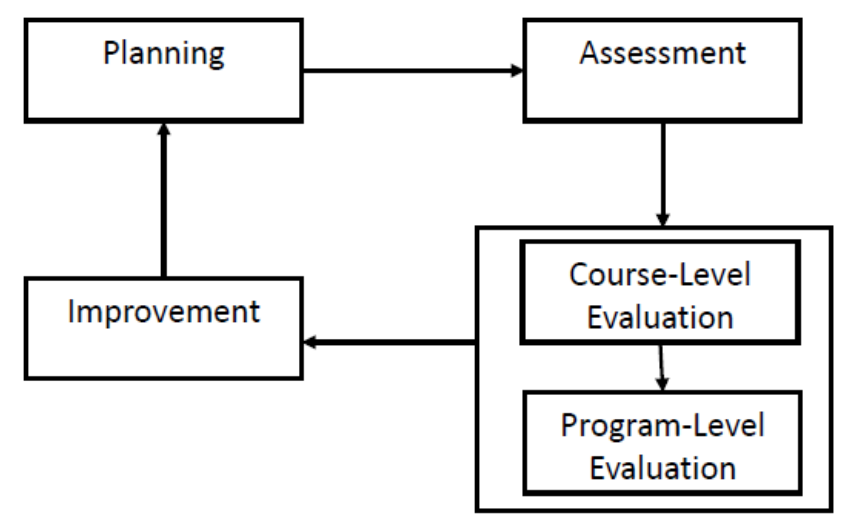

Fig. 12. Assessment and Evaluation Process for Closing the Loop

5) Course-level Evaluation/Improvement: Course instructors write end-of-semester reports taking into account the degree to which the evaluation results meet the pre-set targets $60 \%$ minimum section, failing which the underlying causes are diagnosed and appropriate corrective measures are suggested. These reports also take into account the feedback of students acquired through Student Course surveys, and overall delivery of the course. In the subsequent semester, the suggested corrective measures are implemented which are the driving force for the continuous improvement process. To this end, the Coordinator of the Quality Assurance and Academic Accreditation Unit at the IS department collects the course portfolios and reports and the Continuous Improvement Committee reviews the course reports that include any recommendations and enhancement by the IS department members. This cycle is held toward the end of every semester. The Continuous Improvement Committee meets to talk about remarks and input from the students' achievement of SOs, Student Course outcomes and Exit Surveys. The committee talks about regions of strength, regions for development, and chooses actions for improving SOs.

6) Program-level Evaluation/Improvement: Planning for Fall/ Spring Semester: The department council not only takes the course-level reports into account, but also sheds light on the overall strengths and weaknesses of the program and recommends the necessary actions to rectify such weaknesses. For this purpose the council members meet from time to time to review and to plan for following semesters. During such meetings, the council also reviews feedbacks acquired from constituents and some other initiatives at the university or public level. Examples of outcomes of such meetings include, but not limited to: 
- The department has realized that, the indirect assessment of the outcomes was based on general surveys of the students. Student Course surveys have been redefined to be more direct and only use questions relating to the course specific SOs as in Fig. 9.

- The College of Computer and Information Sciences and IS department follow the field improvements and ideally utilize this latest data in their courses accordingly contributing towards a dynamic educational plan.

7) Highlights of the enhancements: After rigorous experimentations with the direct and indirect assessment data in last 2-3 years and evaluating the quality assessment tools, the program has realized and implemented various measures. Some of them are summarized here.

- Raised the attainment level for direct assessments to 65\% from $60 \%$.

- Emphasizes on assessment based on various assessment tools.

- Regular follow-up on improvement statements through coordination meetings.

- An examination committee is necessary to peruses appropriateness of questions targeting the respective SOs. Therefore, the program constituted the Examination Committee by the end of every Semester for this purpose. The Committee reviewed the questions to SO mappings and suggested improvements, which were then implemented in the respective courses.

\section{ABET VISIT}

The IS program committees prepared the self study report (SSR) of IS program and then submitted them to ABET on July 2019. The SSR of IS program showed significant achievements of IS program outcomes for students and graduates. In December 2019, ABET team visited the college CIS and evaluated IS program and inspected the documents and facilities of the college and the university. In their exit statement, the ABET team stated that no observed weaknesses nor concerns were found through the program. The results of direct and indirect assessment have provided significant evidences of the improved teaching and learning[6].

\section{VI.CONCLUSION}

This paper showed the experiences gained in developing and performing the continuous improvement process that based on PEOs and SOs assessment and evaluation for the IS program to achieve the skills, knowledge and behavior that the students gain

\section{REFERENCES}

[1] Abet-cac (2018). criteria for accrediting computing programs. abet.

[2] https://www.abet.org/accreditation/.

[3] G. K Cunningham. Educational and psychological measurement. macmillan publishing. 1986.

[4] J.J. Fitzpatrick, E.P. Byrne, and D. Kennedy.

[5] Y. Hadi. Seeking abet accreditation of manufacturing and mechanical maintenance technology programs at yanbu industrial college. 2010.

[6] Md. Huq, Chunli Su, Junxia Li, and Most. Sinthia Sarven.

Arsenic enrichment and mobilization in the holocene alluvial aquifers of prayagpur of southwestern bangladesh. Int. Biodeteriorat. Biodegradat, 128:186-194, 2018.

[7] R. J. McBeath. Instructing and evaluating in higher education. A guidebook for planning learning outcomes. Educational Technology Publications.

[8] Javed A. Memon, R. Esra Demirden, and B.S. Chowdhry.

[9] G. Rogers. Student outcomes and performance indicators. abet. 2012.

[10] Rafael E. Vsquez, Fabio Castrilln, Santiago Ra, Norha L. Posada, and Carlos A. Zuluaga.

[11] Kellam N. Sochacka N. Radcliffe D. Walther, J. [12] Atrens A. Yeomans, S.R.

[13] C. F. Yokomoto and W. D. Bostwick. Modeling the process of writing measurable outcomes for ec 2000. 1:11B1/18-11B1/22 vol.1, 1999. 